\title{
Treatment for Type IV Coronary Perforation during Percutaneous Coronary Intervention
}

\author{
Roberto Ramos Barbosa ${ }^{1}$, Ricardo Costa ${ }^{2}$, Juliano Rasquin Slhessarenko ${ }^{3}$, \\ Felipe M. Coelho ${ }^{4}$, Fausto Feres ${ }^{5}$
}

\begin{abstract}
We report the case of a 61-year-od male, hospitalized for unstable angina. Coronary angiography showed a severe lesion in the middle third of the left anterior descending coronary artery. Percutaneous coronary intervention was performed with stent implantation. Coronary rupture was observed with contrast spilling to the left ventricle (type IV coronary perforation) immediately after balloon post-dilatation. After partial heparin reversal with protamine and prolonged balloon inflation at low pressure, coronary rupture was controlled, with a good final angiographic result. Subsequent echocardiography showed minimal pericardial effusion. Post-procedure clinical follow-up was satisfactory.
\end{abstract}

RESUMO

\section{Tratamento de Perfuração Coronária Tipo IV Durante Intervenção Coronária Percutânea}

Relatamos o caso de um paciente de 61 anos de idade, hospitalizado por angina instável. Cineangiocoronariografia demonstrou lesão obstrutiva grave no terço médio da artéria descendente anterior. Intervenção coronária percutânea foi realizada com implante de stent. Logo depois da pós-dilatação com cateter-balão, observou-se ruptura coronária, com extravasamento de contraste para o ventrículo esquerdo (perfuração coronária tipo IV). Após reversão parcial da heparina com protamina e insuflação prolongada do cateter-balão com baixa pressão, a ruptura coronária foi controlada, com bom resultado angiográfico final. Ecocardiografia realizada em seguida evidenciou derrame pericárdico mínimo. A evolução clínica foi satisfatória após o procedimento.

DESCRITORES: Angioplastia. Stents. Ruptura. Vasos coronários.
C oronary perforation is a dreaded and potentially serious complication of percutaneous coronary interventions ( $\mathrm{PCls})$, with high rates of morbidity and mortality. ${ }^{1}$ Perforation or frank rupture of coronary arteries are rare, occurring in $0.1 \%$ to $0.6 \%$ of patients undergoing $\mathrm{PCl}$, reaching up to $3 \%$ of cases involving atheroablative techniques. ${ }^{1-5}$ The present study reports a case of coronary rupture (Ellis type IV perforation) draining into the left ventricle, successfully treated during the intervention.

\section{CASE REPORT}

Male patient, 61 years of age, smoker and hypertensive, who underwent coronary artery bypass graft (CABG) in 2002 (free radial artery graft to the left anterior descending artery, as a " $Y$ " saphenous vein graft to the first marginal branch of the left circumflex artery) after an acute myocardial infarction without ST-segment elevation. He was admitted at another hospital in early November 2011, with a diagnosis of unstable angina. On that occasion, he remained under

\footnotetext{
${ }^{1}$ Interventionist cardiologist physician at the Interventional Cardiology Hemodynamic Service of Instituto de Cardiologia do Espírito Santo. Vitória, ES, Brazil.

2 Doctor. Interventionistl cardiologist physician at Instituto Dante Pazzanese de Cardiologia. São Paulo, SP, Brazil.

${ }^{3}$ Interventionist cardiologist physician at CINECOR. Cuiabá, MT, Brazil.

${ }^{4}$ Resident physician at the Invasive Cardiology Service of Instituto Dante

Pazzanese de Cardiologia. São Paulo, SP, Brazil.
}

\footnotetext{
${ }^{5}$ Doctor. Interventionist cardiologist physician at the Invasive Cardiology Service of Instituto Dante Pazzanese de Cardiologia. São Paulo, SP, Brazil

Correspondence to: Roberto Ramos Barbosa. Av. Marechal Campos, 1.579 - Santa Cecília - Vitória, ES, Brazil - CEP 29043-260

E-mail: roberto.rb@cardiol.br
}

Received on: 8/22/2012 • Accepted on: 11/28/2012 
clinical treatment, with the use of acetylsalicylic acid, clopidogrel, enoxaparin, carvedilol, captopril, amlodipine, and simvastatin. He was discharged after 72 hours with a scheduled coronary angiography within ten days.

The coronary angiography was performed at the Instituto Dante Pazzanese de Cardiologia using a 6F femoral sheath, which demonstrated the absence of significant atherosclerotic disease in the left main coronary artery, left circumflex artery, and right coronary artery; severe stenosis in the middle third of the left anterior descending artery (Figure 1), with mild calcification, eccentricity and poststenotic dilatation; and ostial occlusion of the composite graft to the left anterior descending artery and first marginal branch of the left circumflex artery. Left ventriculography showed a slight reduction in left ventricular systolic function at the expense of mild overall deficit. Lesion assessment by quantitative coronary angiography (QCA) was performed off-line, using the CMS-GFT ${ }^{\mathrm{TM}}$ system, release 5.1 (Medis - Leiden, the Netherlands), which showed proximal reference diameter of 3.36 $\mathrm{mm}$, distal reference diameter of $4.11 \mathrm{~mm}$, reference vessel diameter of $3.94 \mathrm{~mm}$, minimum lumen diameter of $1.16 \mathrm{~mm}$, stenosis area of $91.1 \%$, and stenosis diameter of $70.6 \%$ (Figure 2).

After cardiac catheterization, it was decided, at a meeting involving clinical cardiologists and clinical interventionists, to perform a $\mathrm{PCl}$ to the left anterior descending artery.

\section{Procedure}

The PCl was performed on November 22, 2011, through right radial approach, using a $6 \mathrm{~F}$ sheath and Launcher EBU 3.5 guide-catheter (Medtronic Inc. Minneapolis, USA). A 0.014-inch PT2 moderate support guidewire (Boston Scientific - Natick, USA) was introduced and passed across the lesion in the left anterior descending artery, with direct implantation of a $4.0 \times 24$ $\mathrm{mm}$ Liberté $^{\mathrm{TM}}$ stent (Boston Scientific - Natick, United States) in the middle third of the anterior descending artery up to $12 \mathrm{~atm}$ (Figure 3A). Post-dilation was then performed with a $4.0 \times 10 \mathrm{~mm} \mathrm{Hiryu}^{\circledast}$ balloon catheter (Terumo - Tokyo, Japan) up to 18 atm (Figure 3B), after which the patient complained of acute and intense chest pain. QCA analysis was performed off-line after the procedure, showing a balloon-artery ratio of 1.07 . A control angiography showed coronary rupture in the middle third of the left anterior descending artery, with extravasation as a continuous gush of contrast filling the left ventricular cavity (Ellis type IV coronary perforation) (Figure 3C and D). The balloon used for the post-dilation was quickly reinflated at the rupture site at low pressure (6 atm) (Figure 4A), which was maintained for 40 minutes. Partial reversal of unfractionated heparin with protamine sulfate was also performed. The right femoral artery was quickly accessed with a
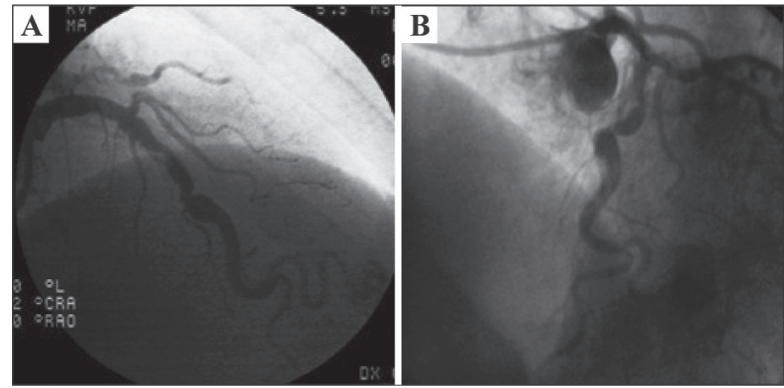

Figure 1 - Cranial view showing severe stenosis in the middle third of the left anterior descending artery.

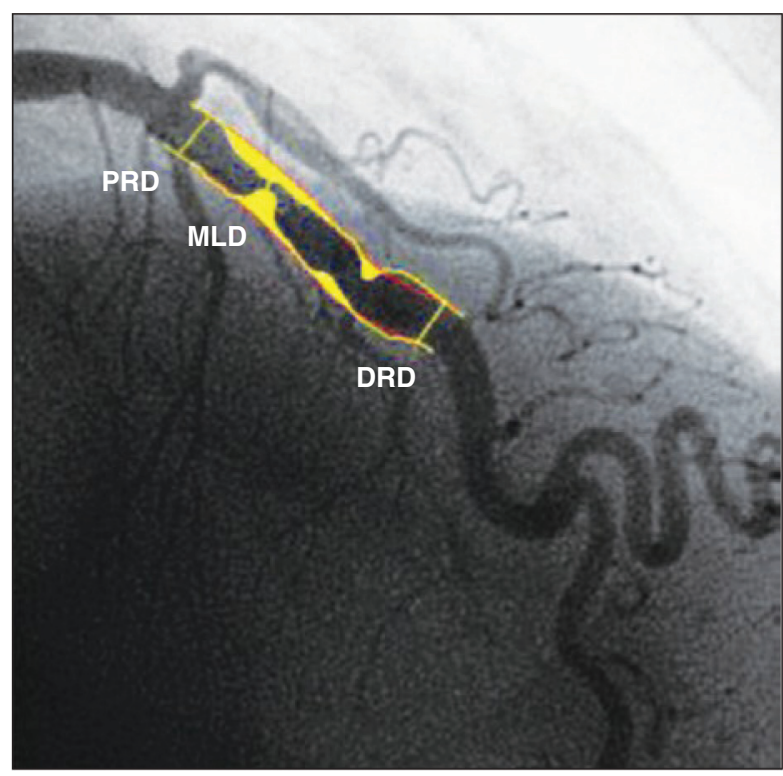

Figure 2 - Quantitative coronary angiography of the left anterior descending lesion. Proximal reference diameter $(P R D)=3.36 \mathrm{~mm}$, distal reference diameter $(D R D)=4.11 \mathrm{~mm}$, reference vessel diameter = $3.94 \mathrm{~mm}$, minimum lumen diameter $(\mathrm{MLD})=1.16 \mathrm{~mm}$, stenosis area $=91.1 \%$, and stenosis diameter $=70.6 \%$.
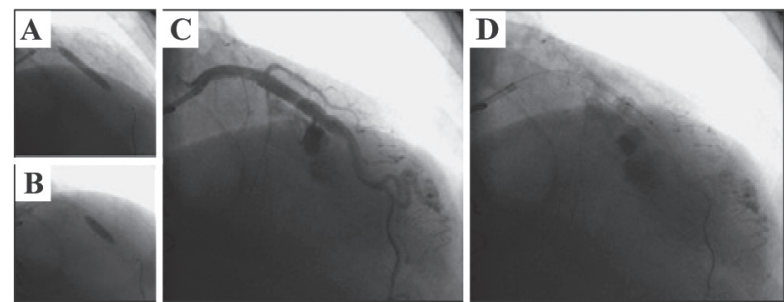

Figure 3 - In A, direct implantation of a $4.0 \times 24 \mathrm{~mm}$ Liberté $^{\mathrm{TM}}$ stent in the middle third of the left anterior descending artery up to $12 \mathrm{~atm}$. In B, post-dilation with $4.0 \times 10 \mathrm{~mm} \mathrm{Hiryu}^{\circledast}$ balloon catheter up to $18 \mathrm{~atm}$. In $\mathrm{C}$ and $\mathrm{D}$, control angiography showing coronary rupture in the middle third of the left anterior descending artery, with continuous extravasation of contrast filling the left ventricular cavity (Ellis type IV coronary perforation)

$7 \mathrm{~F}$ sheath and the Judkins left 4.0 7F guide catheter was advanced to the left coronary sinus (double-guide 

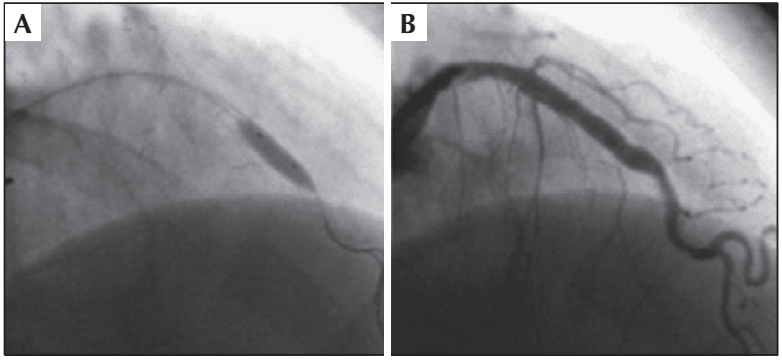

Figure 4 - In $\mathrm{A}$, balloon reinsufflation used for post-dilation at the site of rupture at low pressure. In B, control angiography disclosing coronary rupture resolution and satisfactory angiographic result, with TIMI 3 flow.

catheter technique). Subsequently, the $6 \mathrm{~F}$ guide catheter was retrieved without deflating the balloon, and the left coronary artery was subselectively intubated with a 7F catheter; through that, a second 0.014-inch guide wire (BMW; Abbott Vascular - Temecula, United States) was advanced to the containment balloon, and, in a synchronized maneuver, the balloon was deflated, the second guide wire was crossed, and the containment balloon was reinflated (in order to minimize leakage of blood into the pericardium and the left ventricle). This second 0.014-inch guidewire would be used for delivering a coated stent (if necessary for the occlusion of the coronary rupture), minimizing the time of deflation of the containment balloon.

During prolonged balloon inflation, the patient remained hemodynamically stable, with no signs of cardiac tamponade, and there was improvement in chest pain. After balloon deflation, the patient had cardiorespiratory arrest in ventricular fibrillation, successfully reversed after prompt defibrillation with 200 J (biphasic) and cardiopulmonary resuscitation for 2 minutes, with return to responsive sinus rhythm with hemodynamic stability, spontaneous ventilation, arterial oxygen saturation of $96 \%$, blood pressure of $110 / 80$ $\mathrm{mmHg}$, and asymptomatic. Control angiography revealed resolution of coronary rupture, the absence of any contrast extravasation, left anterior descending artery with no residual lesion in the middle third and TIMI 3 flow (Fig. 4B). There was no need for coated stent implantation in the coronary rupture site. Transthoracic echocardiography performed in the catheterization lab showed minimal pericardial effusion.

After the procedure, the patient remained hospitalized in the Coronary Care Unit of the institution for 52 hours, with satisfactory clinical evolution, despite the diagnosis of periprocedural myocardial infarction (creatine kinase $\mathrm{MB}$ fraction [CK-MB] mass, $51 \mathrm{ng} / \mathrm{mL}$; reference value, $4.1 \mathrm{ng} / \mathrm{mL}$; troponin I, $0.57 \mathrm{ng} / \mathrm{mL}$; reference value, $0.1 \mathrm{ng} / \mathrm{mL}$ ). No other complications were observed, and transthoracic echocardiographies performed 24 and 48 hours after the procedure showed no pericardial effusion, and normal systolic and diastolic left ventricular function. The patient was discharged three days after the $\mathrm{PCl}$, when a significant decrease in myocardial necrosis markers was observed.

The patient returned 30 days after the $\mathrm{PCI}$ procedure for outpatient consultation. He remained asymptomatic, using acetylsalicylic acid $100 \mathrm{mg}$, clopidogrel $75 \mathrm{mg}$, atenolol $50 \mathrm{mg}$, enalapril $20 \mathrm{mg}$ every 12 hours, amlodipine $10 \mathrm{mg}$, and simvastatin $40 \mathrm{mg}$. Clopidogrel was then suspended, while the other medications were maintained. Clinical monitoring performed by telephone on May 4, 2012 showed no adverse cardiac events at the six-month follow-up.

\section{DISCUSSION}

Coronary perforation, albeit rare, is a severe and dramatic complication of $\mathrm{PCl}$. In at least half of the cases it is caused by the intracoronary guide wire, ${ }^{6}$ and the use of atheroablation devices predisposes to this complication at higher frequency $(1 \%$ vs. $0.2 \%$ when they are not used, $\mathrm{P}<0.001) .{ }^{6}$ In the case of coronary perforation, impending cardiac tamponade requires rapid and accurate measures by the interventionist, at the risk of emergency surgery or death of the patient.

Ellis et al. ${ }^{1}$ were the first to report, in 1994, the association between coronary perforations in PCls and high incidence of major adverse events. In that study, the authors also proposed a classification of perforations, which is used to date: type I, extraluminal cavity without contrast extravasation ( $8 \%$ risk of tamponade); type II, presence of pericardial blush and myocardium without contrast extravasation (13\% risk of tamponade); type III, contrast extravasation through outflow tract orifice $>1 \mathrm{~mm}$ (up to $63 \%$ risk of tamponade); and type IV, perforation draining into a heart chamber or coronary sinus (cavity spilling).

In addition to the atheroablative techniques, coronary perforation is associated with other risk factors related to the clinical features, the anatomy, and the technical approach, such as older age, female gender, chronic total occlusions, calcified lesions, significant tortuosity, use of high release or post-dilation pressures, balloon oversizing (balloon-artery ratio > 1.2), high pressure off the edges of the stent, and stenting in vessels with significant loss of distal calibre (tapering). ${ }^{3,5-7}$

Dippel et al., ${ }^{3}$ in a series of 6,214 procedures performed between 1995 and 1999, observed that mortality was limited to the type III perforation subgroup; no patient with type II perforation required emergency surgery or died. Mortality was $11.1 \%$, need for emergency CABG was $22.2 \%$, and the incidence of cardiac tamponade was $22.2 \%$. In the series of coronary perforation cases reported by Stankovic et al., ${ }^{5}$ the mortality rate was $8 \%$, incidence of myocardial infarction was $18 \%$, and CABG was necessary in $13 \%$ of cases. Witzke et al. ${ }^{6}$ reported, in their series, 39 
perforations in 12,658 patients $(0.3 \%)$. The mortality rate was $2.6 \%$, the emergency surgery rate was $5.2 \%$, and pericardial effusion occurred in 18 patients $(46.2 \%)$, progressing to cardiac tamponade in seven (17.5\%). The use of glycoprotein IIb/IIla inhibitors did not change the outcome in this series, regarding adverse outcomes after coronary perforation. Silva et al. ${ }^{8}$ recently reported on the Brazilian experience when handling coronary perforations in a center with a high volume of procedures. Of a total of 5,585 patients undergoing $\mathrm{PCl}, 18$ had coronary perforation (incidence of $0.32 \%$ ), with no deaths. Emergency surgery was necessary in 5.6\% of cases. Female gender, history of chronic obstructive pulmonary disease, and chronic occlusions were identified as predictors of coronary perforation. The observation of a chronological decrease in mortality in the series of reported cases can be explained both by the technological advancements of the specialty (the use of progressively smaller and more delicate devices and decrease in the use of atheroablative techniques) and the advent of coated stents and their positive impact on coronary perforation management.

Regarding the management and treatment, several authors have shown that the majority of the Ellis types I and II perforations can be conservatively treated, through reversal of unfractionated heparin with protamine (recommended dose: $1 \mathrm{mg}$ intravenously for each 100 units of unfractionated heparin administered), prolonged inflation with balloon catheter, and the use of coils and/ or stents when necessary. Types III and IV perforations may have major complications, often requiring more invasive measures, such as surgery and emergency pericardiocentesis. ${ }^{2,9-11}$ Transthoracic echocardiography is recommended while still in the catheterization lab, as well as other serial testing in the intensive care unit, due to the possibility of late formation of large pericardial effusion, which may cause hemodynamic compromise. $^{8}$

Some emergency measures must be taken sequentially before the diagnosis of coronary perforation during $\mathrm{PCI}$, such as heparin reversal, low-pressure prolonged inflation (at least 10 minutes) of the balloon catheter at the perforation site, discontinuing or reversing glycoprotein Ilb/IIla inhibitors, performance of urgent echocardiography, and performance of urgent pericardiocentesis if there are signs of cardiac tamponade. Heparin reversal is somewhat controversial, particularly with minor perforations, due to risk of acute stent thrombosis. Platelet transfusion is a good strategy to reverse glycoprotein IIb/IIla inhibitors when using tirofiban or eptifibatide, which are highly specific for the IIb/IIla receptor, with a half-life of two to three hours. ${ }^{12}$ However, it is worth remembering that abciximab has a long half-life (seven hours) and high affinity for the IIb/IIla receptor, which can make it a less effective measure when this drug is used. ${ }^{13}$ If the perforation is not occluded, it is possible to use coated stent or microcoil implantation to occlude the perforation. ${ }^{14} \mathrm{CABG}$ is indicated if these measures are not successful in controlling the perforation.

The use of coated stents for the treatment of coronary perforation has shown satisfactory results, with success rates $>90 \%$. Currently, this is the treatment of choice for Ellis type III perforations in arteries $>2 \mathrm{~mm} .{ }^{15}$ More modern possible techniques include device delivery through a $5 \mathrm{~F}$ guide catheter (deeply intubated into the coronary artery) inside 6F or 7F guide catheters (motherand-child technique), as the high profile and reduced flexibility compromise the manoeuvres and the delivery capacity of the coated stent. ${ }^{16}$ The double-guide catheter technique may be used to minimize blood leakage into the pericardial when the coated stent implantation is necessary. ${ }^{17}$ This technique consists of a subselective catheterization of the coronary artery ostium through a second guide catheter, after obtaining a second access route, while keeping the containment balloon inflated at the perforation site. Through this catheter, the coated stent is delivered to seal the perforation. In the present case, the double-guide catheter technique was used, but the coated stent was not necessary, considering the complete resolution of coronary perforation at the control angiography after prolonged balloon inflation.

The reported case is relevant, as it documents a coronary perforation with extravasation of contrast medium into the left ventricle (Ellis type IV coronary perforation), a very rare complication. The probable cause of the rupture was the post-dilation at high pressure, reaching a high balloon-artery ratio. Although potentially severe, the event was well-managed and solved with the initial measures. The prolonged inflation time of the containment balloon had a determinant role in the perforation control, and there was no need for coated stent implantation. However, this necessity was foreseen, and, therefore, the double-guide catheter technique was employed, aiming at minimal interruption of balloon inflation at the perforation site. Cardiac arrest in ventricular fibrillation was attributed to reperfusion of the left anterior descending artery after cuff deflation. With immediate defibrillation, the rapid success of cardiopulmonary resuscitation prevented any neurological deficit, with very good long-term prognosis. The finding of periprocedural myocardial infarction was demonstrated by elevated markers of myocardial necrosis, which at first were attributed to prolonged myocardial ischaemia resulting from containment balloon inflation. Nevertheless, this alteration should be considered a consequence of the complication that occurred, which evolved asymptomatically and without hemodynamic or electrical involvement.

It can be concluded that the successful treatment of this serious complication requires attention and rapid decision-making by the interventional cardiologist. Early detection of coronary perforation is crucial in order to perform prompt coronary artery occlusion with containment balloon. Heparin neutralization, albeit partial, can 
be performed, as well as platelet transfusion in cases associated with the use of glycoprotein Ilb/IIla inhibitors and the use of coated stents. By becoming acquainted with these measures, the interventional cardiologist can prevent emergency surgery in most cases of coronary perforation and reduce morbidity and mortality from this complication.

\section{CONFLICT OF INTEREST}

The authors declare no conflicts of interest.

\section{REFERENCES}

1. Ellis SG, Ajluni S, Arnold AZ, Popma JJ, Bittl JA, Eigler NL, et al. Increased coronary perforation in the new device era. Incidence, classification, management, and outcome. Circulation. 1994;90(6):2725-30.

2. Gruberg L, Pinnow E, Flood R, Bonnet Y, Tebeica M, Waksman R, et al. Incidence, management, and outcome of coronary artery perforation during percutaneous coronary intervention. Am J Cardiol. 2000;86(6):680-2.

3. Dippel EJ, Kereiakes DJ, Tramuta DA, BroderickTM, ShimshakTM, Roth EM, et al. Coronary perforation during percutaneous coronary intervention in the era of abciximab platelet glycoprotein IIb/IIla blockade: an algorithm for percutaneous management. Catheter Cardiovasc Interv. 2001;52(3):279-86.

4. Gunning MG, Williams IL, Jewitt DE, Shah AM, Wainwright RJ, Thomas MR. Coronary artery perforation during percutaneous intervention: incidence and outcome. Heart. 2002;88(5):495-8.

5. Stankovic G, Orlic D, Corvaja N, Airoldi F, Chieffo A, Spanos $\mathrm{V}$, et al. Incidence, predictors, in-hospital, and late outcomes of coronary artery perforations. Am J Cardiol. 2004;93(2): 213-6.

6. Witzke CF, Martin-Herrero F, Clarke SC, Pomerantzev E, Palacios IF. The changing pattern of coronary perforation during percutaneous coronary intervention in the new device era. J Invasive Cardiol. 2004;16(6):257-301.
7. Cohen BM, Weber VI, Relsman M, Casale A, Dorros G. Coronary perforation complicating rotational ablation: the U.S. multicenter experience. Cathet Cardiovasc Diagn. 1996;Supp 3:55-9.

8. Silva WA, Costa RA, Campostrini T, Costa Jr. JR, Siqueira DA Staico R, et al. Incidência, manejo e prognóstico de perfurações coronárias. Rev Bras Cardiol Invasiva. 2012;20(3):295-302.

9. Fasseas P, Orford JL, Panetta CJ, Bell MR, Denktas AE, Lennon RJ, et al. Incidence, correlates, management, and clinical outcome of coronary perforation: analysis of 16,298 procedures. Am Heart J. 2004;147(1):140-5

10. Shimony A, Zahger D, Van Straten M, Shalev A, Gilutz H, Ilia R, et al. Incidence, risk factors, management and outcomes of coronary artery perforation during percutaneous coronary intervention. Am J Cardiol. 2009;104(12):1674-7.

11. Hendry C, Fraser D, Eichhofer J, Mamas MA, Fath-Ordoubadi F, El-Omar $\mathrm{M}$, et al. Coronary perforation in the drug-eluting stent era: incidence, risk factors, management and outcome: the UK experience. Eurolntervention. 2012;8(1):79-86.

12. Peter K, Schwarz M, Ylanne J, Kohler B, Moser M, Nordt T, et al. Induction of fibrinogen binding and platelet aggregation as a potential intrinsic property of various glycoprotein $\mathrm{llb} /$ IIla (alphallbbeta3) inhibitors. Blood. 1998;92(9):3240-9.

13. Coller BS. Potential non-glycoprotein IIb/IIla effects of abciximab. Am Heart J. 1999;138(1 Pt 2):S1-5.

14. Yeo KK, Rogers JH, Laird JR. Use of stent grafts and coils in vessel rupture and perforation. J Interv Cardiol. 2008;21(1): 86-99.

15. Lansky AJ, Yang YM, Khan Y, Costa RA, Pietras C, Tsuchiya Y, et al. Treatment of coronary artery perforations complicating percutaneous coronary intervention with a polytetrafluoroethylene-covered stent graft. Am J Cardiol. 2006;98(3):370-4.

16. Fujimoto Y, Matsudo Y, Kobayashi Y. Successful delivery of polytetrafluoroethylene-covered stent through 5 French guiding catheter. J Invasive Cardiol. 2012;24(9):E199-201.

17. Mozer GW, Paula JET, Teixeira MA, Caetano Jr CS, Souza JBS, Maranha SR, et al. Uso de duplo cateter-guia como auxílio para tratamento de perfuração coronariana durante angioplastia primária. Rev Bras Cardiol Invasiva. 2007;15(3):297-301. 